\title{
Non-apnoeic REM sleep induced nocturnal oxygen desaturation treated by nasal continuous positive airway pressure
}

\author{
F SÉRIÈS, Y CORMIER, J LA FORGE \\ From l'Unité de Recherche, Centre de Pneumologie, Hôpital Laval, Sainte-Foy, Quebec, Canada
}

\begin{abstract}
Non-apnoeic oxygen desaturation related to rapid eye movement (REM) sleep in a patient with hypothyroidism, obesity, respiratory failure, and cardiac failure was improved by treatment with nasal continuous positive airway pressure of $10 \mathrm{~cm} \mathrm{H}_{2} \mathrm{O}$.
\end{abstract}

Sleeping non-apnoeic arterial oxygen desaturation occurs frequently in patients with chronic obstructive or restrictive pulmonary disease. ${ }^{12}$ The largest falls in oxygen saturation $\left(\mathrm{SaO}_{2}\right)$ occur during rapid eye movement (REM) sleep. These episodes of arterial desaturation are believed to have an important role in the development of pulmonary hypertension and right heart dysfunction. ${ }^{3}$

The occurrence of oxygen desaturation during REM sleep may be explained by the loss of skeletal muscle tone. ${ }^{4}$ Reduced activity of intercostal and other accessory muscles at night may lead to alveolar hypoventilation in patients with lung disease. ${ }^{5}$ Loss of upper airway muscle tone can also increase upper airways resistance and inspiratory work load, ${ }^{6}$ and may reduce alveolar ventilation further. Changes in muscle tone during REM sleep may lead to a reduction in functional residual capacity (FRC) to below closing capacity, resulting in an increase in ventilation-perfusion inequalities and intrapulmonary shunting. ${ }^{7}$

We wondered whether nocturnal continuous positive airway pressure (CPAP) could reduce episodes of REM sleep related oxygen desaturation. CPAP could improve oxygen saturation by splinting the upper airways. This should prevent any increase in resistance of the upper airways, by increasing FRC and reducing venous admixture. We report a patient with nocturnal non-apnoeic arterial oxygen desaturation who was improved by $10 \mathrm{~cm} \mathrm{H}_{2} \mathrm{O}$ nasal continuous positive airway pressure.

\section{Case report}

A 64 year old man with severe hypersomnia was referred for sleep studies. He was very obese ( $198 \%$ of ideal body weight) and was an habitual loud snorer. He had smoked 1 pack of cigarettes a day for $\mathbf{4 0}$ years. Symptoms included chronic cough and sputum production, grade III/IV dyspnoea, morning headaches, and daytime hypersomnolence. Physical examination showed a short neck and a hypertrophic tongue and uvula with a reduction in the oropharyngeal aperture.

Address for reprint requests: Dr Frédéric Sériès, Centre de Pneumologie, Hôpital Laval, 2725, chemin Ste-Foy, Ste-Foy, Quebec, Canada GIV 4G5.

Accepted 23 January 1989
There were diffuse rhonchi and signs of right heart failure. Attempts to carry out pulmonary function tests were unsuccessful: the patient could neither understand the instructions nor coordinate his efforts. Arterial blood gases analysis (sitting position) showed oxygen tension $\left(\mathrm{PaO}_{2}\right)$ to be $5.6 \mathrm{kPa}$, carbon dioxide tension $\left(\mathrm{PaCO}_{2}\right) 8.8 \mathrm{kPa}, \mathrm{pH} \mathrm{7.34}$, and bicarbonate $35.5 \mathrm{mmol} / \mathrm{l}$. Thyroid function tests indicated primary hypothyroidism: thyroxine 2.7 (normal range 78 158) mmol)l, triiodothyronine $0.78(1.54-3.07) \mathrm{mmol} / \mathrm{l}$, thyroid stimulating hormone $43(7-0.4) \mathrm{mU} / \mathrm{l}$. The electrocardiogram (ECG) showed right axis deviation and partial right bundle branch block. The patient was treated with bronchodilators and diuretics. An initial polysomnographic study, performed with the patient breathing room air, included a determination of sleep stages, measurement of oxygen saturation with an ear oximeter (Biox II, Ohmeda), nasal and mouth flows (thermocouples), thoracoabdominal movements (inductance vest calibrated by the least square method), and a continuous ECG. Sleep stages and abnormal respiratory events were defined by standard criteria. ${ }^{8}$ The results are reported in the table. Episodes of apnoea occurred only during stage I-II and were exclusively obstructive in type. They were associated with episodes of ventricular tachycardia. The largest falls in $\mathrm{SaO}_{2}$ were recorded during REM sleep, and were not related to apnoea. As $\mathrm{SaO}_{2}$ fell below $60 \%$, the lower limit of linearity of our oximeter, the falls could not be quantified. The percentage of REM sleep time spent at an $\mathrm{SaO}_{2}$ below $90 \%$ illustrates the severity of these non-apnoeic desaturations (fig). The ECG remained normal thoughout REM sleep.

Results of the diagnostic and continuous positive airway pressure (CPAP) polysomnographic studies

\begin{tabular}{|c|c|c|}
\hline & $\begin{array}{l}\text { Diagnostic } \\
\text { night }\end{array}$ & $\begin{array}{l}C P A P \\
\left(10 \mathrm{~cm} \mathrm{H}_{2} \mathrm{O}\right)\end{array}$ \\
\hline $\begin{array}{l}\text { Total sleep time (TST) (h) } \\
\text { Sleep period time (SPT) (h) } \\
\text { Sleep efficiency }(\%)^{*} \\
\text { Stage I-II sleep }(\% \text { TST) } \\
\text { Stage III-IV sleep }(\% \text { TST) } \\
\text { REM sleep }(\% \text { TST) } \\
\text { Apnoea index } \dagger \\
\text { Apnoea hypopnoea index } \dagger \\
\text { Mean apnoea duration (S) } \\
\text { Lowest REM SaO }(\%)_{\ddagger}^{\ddagger} \\
\text { Lowest postapnoeic } \mathrm{SaO}_{2}(\%)\end{array}$ & $\begin{array}{c}5 \cdot 1 \\
7 \cdot 9 \\
64 \cdot 5 \\
78 \cdot 0 \\
4 \cdot 1 \\
17 \cdot 9 \\
3 \cdot 6 \\
29 \cdot 2 \\
42 \\
<60 \\
66\end{array}$ & $\begin{array}{r}5 \cdot 4 \\
7 \cdot 3 \\
73 \cdot 9 \\
84 \cdot 0 \\
4 \cdot 5 \\
11 \cdot 5 \\
2 \\
19 \cdot 8 \\
27 \\
69 \\
73\end{array}$ \\
\hline
\end{tabular}

* The ratio total sleep time/time in bed.

+ Number of episodes per hour of sleep.

† The lowest levels of $\mathrm{SaO}_{2}$ were reached during REM sleep and were not related to apnoea. 


\section{\% REM sleep time}

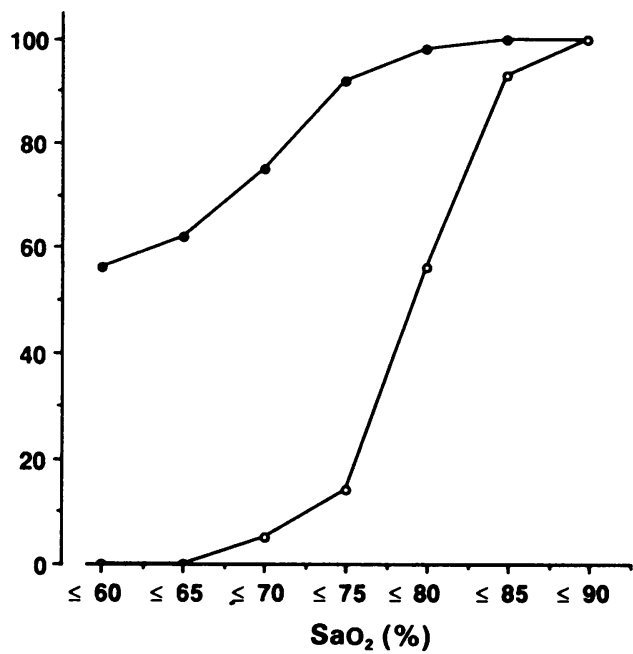

Cumulative percentages of REM sleep spent at each level of arterial oxygen saturation $\left(\mathrm{SaO}_{2}\right)$ on the diagnostic night $(-)$ and the night when nasal continuous positive airway pressure $\left(10 \mathrm{~cm} \mathrm{H}_{2} \mathrm{O}: \mathrm{O}-\mathrm{O}\right)$ was used. The shift of this curve with continuous positive airway pressure indicates that less time was spent at each oxygen saturation values.

A second polysomnographic study was performed with the patient receiving nasal continuous positive airway pressure (Sleep Easy II Nasal CPAP, Respironics). There were no other changes in treatment between the two sleep studies; both were performed before thyroid replacement treatment The positive pressure was increased progressively from 0 to $10 \mathrm{~cm} \mathrm{H}_{2} \mathrm{O}$. Non-apnoeic oxygen desaturation during REM sleep diminished progressively with increasing nasal continuous positive airway pressure. The lowest $\mathrm{SaO}_{2}$ value during

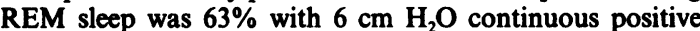
airway pressure and $69 \%$ with $10 \mathrm{~cm} \mathrm{H}_{2} \mathrm{O}$. The improvement in oxygen saturations with nasal continuous positive airway pressure is illustrated in the figure. Continuous positive airway pressure of $10 \mathrm{~cm} \mathrm{H} \mathrm{H}_{2} \mathrm{O}$ did not eliminate non-REM sleep apnoeic events (table) but the patient was unable to tolerate higher pressures. The ECG abnormalities related to apnoeic events disappeared with continuous positive airway pressure.

Nasal continuous positive airway pressure resulted in clinical improvement, abolishing hypersomnia and morning headache and subjectively improving the quality of sleep. Severe respiratory abnormalities persisted with continuous positive airway pressure, however, so it was not considered for home treatment. After two months of thyroid replacement treatment the patient's sleep related breathing disorders improved: apnoea-hypopnoea index was 25 and the lowest $\mathrm{SaO}_{2}$ reached during REM sleep was $60 \%$.

\section{Discussion}

Our patient had morbid obesity, hypothyroidism, and a sleep apnoea syndrome ${ }^{9}$ with severe non-apnoeic arterial oxygen desaturation during REM sleep. The association of an obstructive sleep apnoea syndrome and non-apnoeic falls in $\mathrm{SaO}_{2}$ during REM sleep has been reported in patients with coexistent chronic obstructive lung disease. ${ }^{10}$ Non-apnoeic oxygen desaturation during REM sleep is well described in obstructive and restrictive lung diseases. ${ }^{12}$ Nocturnal oxygen desaturations secondary to obstructive apnoea or hypopnoea has been reported in hypothyroidism." "12 We believe that our patient had pulmonary disease (severe dyspnoea, hepatojugular reflux, diffuse rhonchi, hypoxaemia with hypercapnia, and respiratory acidosis).

The percentage of total sleep time spent in REM sleep fell with continuous positive airway pressure $(17.9 \%$ during the initial study, $11.5 \%$ with nasal continuous positive airway pressure). We do not believe that this was the cause of the improvement in oxygen saturation because we observed a progressive improvement in $\mathrm{SaO}_{2}$ during one $\mathrm{REM}$ cycle after the continuous positive airway pressure level had been increased.

The mechanism underlying oxygen desaturation during REM sleep is similar in obstructive and restrictive pulmonary diseases; similar mechanisms could therefore account for the improvement in the fall in $\mathrm{SaO}_{2}$ during REM sleep with nasa continuous positive airway pressure regardless of the underlying lung disease. The benefits of continuous positive airway pressure could be due to an increase in lung volume with improvement in VA/Q inequalities or to a pneumatic splinting effect of the upper airways.

The place of continuous positive airway pressure in the treatment of nocturnal oxygen desaturations will have to be defined by further studies; it could possibly replace or reduce the need for nocturnal supplementary oxygen in some of these patients.

This work was supported by the Foundation JD Bégin of Laval University.

\section{References}

1 Littner MR, McGinty DJ, Arand DL. Determinants of oxygen desaturation in the course of ventilation during sleep in chronic obstructive pulmonary disease. Am Rev Respir Dis 1980, 122:849-57.

2 George CF, Kryger MH. Sleep in restrictive lung disease. Sleep 1987;10:409-18.

3 Douglas NJ, Calverley PMA, Legett RJE, Brash HM. Transien hypoxemia during sleep in chronic bronchitis and emphysema Lancet 1979; i:1-4.

4 Pompeiano $\mathrm{O}$. The neurophysiological mechanisms of the postural and motor events during desynchronized sleep. Proc Ass Res Nerv Ment Dis 1967;45:351-423.

5 Hudgel DW, Martin RJ, Capchart M, Johnson B, Hill P Contribution of hypoventilation to sleep oxygen desaturation in chronic obstructive pulmonary disease. J Appl Physiol 1983 55:669-77.

6 Hudgel DW, Martin RJ, Johnson B, Hill P. Mechanics of the respiratory system and breathing pattern during sleep in norma humans. J Appl Physiol 1984;561:133-7.

7 Fletcher EC, Gray BA, Levin DC. Non-apneic mechanisms of arterial oxygen desaturation during rapid-eye-movement sleep. J Appl Physiol 1983;54:632-9.

8 Martin RJ. (Chairman). Indications and standards for cardiopulmonary sleep studies. Sleep 1985;8:371-9.

9 Gould GA, Whyte KF, Rhind GB, et al. The sleep hypopnea syndrome. Am Rev Respir Dis 1988;137:895-8.

10 Fletcher EC, Brown DL. Nocturnal oxyhemoglobin desaturation following tracheostomy for obstructive sleep apnea. Am J Med 1985;79:35-42.

11 Skatrud J, Iber C, Ewart R, Thomas G, Rasmussen H, Schultze B Disordered breathing during sleep in hypothyroidism. Am Rev Respir Dis 1981:124:325-9.

12 Rajagopal K, Abbrecht PH, Derderian SS, et al. Obstructive sleep apnea in hypothyroidism. Ann Intern Med 1984;104:491-4. 